\title{
A Rotation Free Image of Triple Polepiece Projector Lens Design
}

\author{
Muna A. Al-Khashab \\ Department of Physics \\ College of Science \\ Mosul University
}

\author{
Zeina T. Arabo
}

Department of Electric

Technology Institute

Mosul / Iraq

(Received 14 / 12 / 2009 ; Accepted 26 /4 /2010 )

\begin{abstract}
The developing of the polepieces structure together with the geometrical parameters for the magnetic electron lenses have led to new possibilities for constructing these lenses which are used in the rotation free images of electron microscope.

The optical properties of asymmetrical magnetic projector lens of triple polepieces geometry and two air gaps of an opposite excitation were studied in detail. Radial distortion was reduced to zero, at a certain excitation, where the projector focal length reached its minimum value. Therefore, the spiral distortion was reduced by changing some parameters of polepiece, so that this lens becomes asymmetrical in shape. Furthermore radial and spiral distortions were eliminated from the lens and the focal length was shortened when the thickness of the middle polepiece $(t)$ and the diameter of the upper polepiece (d1) were changed alternately, the free rotation in the image was obtained.
\end{abstract}

Keywords: polepiece geometrical parameters, triple polepieces lens, flux lines, rotation free image.

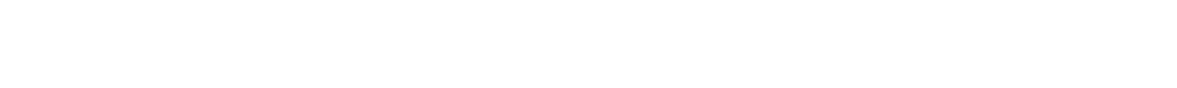

\section{الملذص}

أدى قطوير تركيب أتطلب العهست المغنطيسية ومعلملاتها الهنهية إلى الإمكانيلت الحيثة في صناعة عهست مغنلطيسية ذات صور خالية من الدوران تستخدم في المجاهر الالكترونية.

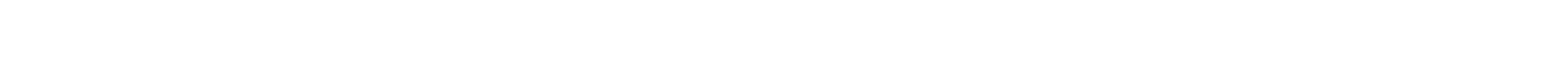

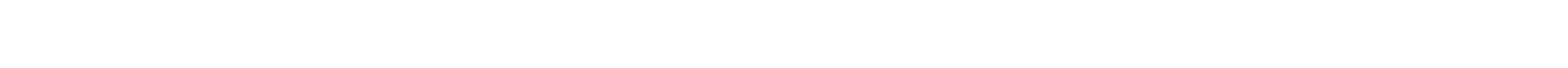

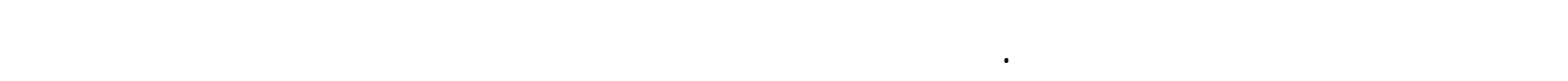

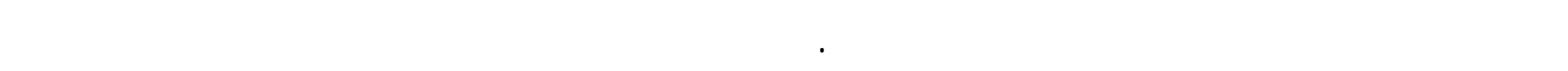

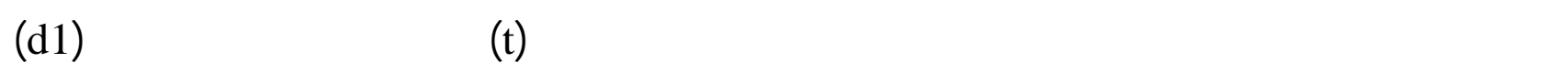
بالتبال، عنئذٍٍ م الحصول على انعدلم دوران الصورة. 